\title{
Mulemba
}

Revista Angolana de Ciências Sociais

\section{A mayombola como arte sobrenatural de enriquecimento: considerações sobre a mercantilização do oculto}

The mayombola as the supernatural art of enrichment: Considerations about the commodification of the occult

\section{Odílio Fernandes}

\section{OpenEdition \\ Journals}

Edição electrónica

URL: http://journals.openedition.org/mulemba/365

DOI: 10.4000/mulemba.365

ISSN: 2520-0305

Editora

Edições Pedago

Edição impressa

Data de publição: 1 maio 2015

Paginação: 101-128

ISSN: 2182-6471

Refêrencia eletrónica

Odílio Fernandes, «A mayombola como arte sobrenatural de enriquecimento: considerações sobre a mercantilização do oculto», Mulemba [Online], 5 (9) | 2015, posto online no dia 21 novembro 2016, consultado o 26 janeiro 2021. URL: http://journals.openedition.org/mulemba/365 ; DOI: https:// doi.org/10.4000/mulemba.365

Este documento foi criado de forma automática no dia 26 janeiro 2021.

Tous droits réservés 


\section{A mayombola como arte sobrenatural de enriquecimento: considerações sobre a mercantilização do oculto}

The mayombola as the supernatural art of enrichment: Considerations about the commodification of the occult

Odílio Fernandes

\section{NOTA DO EDITOR}

Recepção do manuscrito: 04/02/2015

Conclusão da revisão: 30/03/2015

Aceite para publicação em: 06/04/2015

\section{Introdução}

1 Um dos grandes méritos da imprensa angolana nos nossos dias tem sido o de divulgar os problemas sociais quotidianos das populações, na sua generalidade, e de entre esses problemas, notícias sobre actividades sobrenaturais têm sido frequentes e absorvido grandemente a atenção do público, como as que se relacionam com o facto de pessoas consideradas mortas terem sido avistadas novamente vivas. ${ }^{1}$ Rumores sobre a ressurreição de pessoas mortas, assim como de mortos-vivos, são uma constante em Angola, desde tempos imemoriais, mas tais fenómenos não têm atraído sobremaneira a atenção do público porque permanecem fechados nas comunidades onde ocorrem, que se caracterizam por relações sociais íntimas e de forte interacção mútua, que os preservam dentro de si (CHICOADÃO 2005; RIBAS 2009; FIGUEIREDO 2011; MILANDO 2013). Para além disso, até à data da independência nacional tais fenómenos eram 
reprimidos pelas autoridades coloniais (FLORÊNCIO 2010). ${ }^{2}$ Foi apenas em 2001 que um desses casos, ocorrido na província do Kwandu-Kuvangu, passou a ter lugar relevante no imaginário popular como resultado da cobertura que sofreu da imprensa, por ter estado presumivelmente envolvido o governador da província na morte de oito pessoas, que foram fuziladas pelas autoridades locais. Três dessas pessoas foram acusadas de terem morto outras três pessoas para as usarem depois de ressuscitadas como força de trabalho, numa forma deliberada de enriquecimento por meios sobrenaturais. Em 2013, o mesmo fenómeno voltou a ser notícia na província do Zaire, onde um jovem que tinha morrido cerca de um ano antes, voltou aparentemente a aparecer novamente vivo aos seus familiares, afirmando ter estado durante esse tempo a trabalhar numa lavra na província do Uíje depois de ressuscitado. Este caso foi também bastante coberto pela imprensa nacional, tendo voltado a monopolizar as conversas quotidianas e de uma forma bastante alargada, foi grandemente discutido, por ter ocorrido numa era de fácil acesso aos mais diferenciados meios de comunicação e redes sociais informatizadas. Este fenómeno que na parte norte do país se designa «mayombola» ou «matombola» e que tem a designação de «kamutukuleni» no Kwandu-Kuvangu, tem uma estreita relação com as forças do oculto e do sobrenatural, ou seja é um caso particular de feitiçaria (CHICOADÃO 2010: 100; RIBAS 2009: 25).

2 Casos de feitiçaria em Angola têm sido frequentemente registados ao longo dos anos e é um fenómeno que tem aumentado no país nas últimas três décadas (ALTUNA 1985; CARVALHO 1989; DIOCESE DE MENONGUE 1997; MILANDO 2013; SAVE THE CHILDREN 2002; MALUMBU 2005; CHICOADÃO 2005; RIBAS 2009; DOMINGOS 2012). Todas as discussões sobre o oculto compartilham a definição geral de que o feitiço é o uso de poderes sobrenaturais para prejudicar o outro e que se desenvolve num mundo fechado, onde as pessoas se ligam por vínculos sociais íntimos, que traduzem relações de vizinhança, compreendendo preferencialmente círculos de familiares e parentes (WILSON 1951: 256; MAYER 1954: 56; MARWICK 1964: 300; CARVALHO 1989: 281; MILANDO 2013). Do mesmo modo, o feitiço tem também sido entendido como uma forma de poder munido do qual as pessoas controlam o uso de recursos económicos e procuram sucesso nos seus empreendimentos financeiros (SANDERS 1995: 5; MALUMBU 2005: 255; NIEHAUS 2001: 56; RIBAS 2009: 157). E essa compreensão do feitiço é interiorizada por muitos angolanos, já que, para eles, a gestão com sucesso de forças ocultas tem sido desde há muito tempo um pré-requisito lógico para obter e manter estatuto social e riqueza (SANDERS 2001: 162). A acumulação individual de riqueza para esses angolanos tem uma relação estreita com a feitiçaria, já que, tendo em conta o modo de produção camponês e as formas de alienação da terra, historicamente, estes aspectos funcionam como limitantes da acumulação, pelo que esta apenas pode ser explicada por causas ocultas. Fazendo então recurso aos conceitos de economia moral e economia de afeição, os aspectos ligados à assimilação dos modernos sistemas políticoeconómicos que levam à acumulação por tais angolanos, podem ser analisados focando a ligação indissolúvel que existe entre a economia de subsistência camponesa e as questões morais a ela subjacentes.

3 É, pois, a ligação do feitiço com o mercado e com a ordem capitalista, que é analisada neste artigo, ${ }^{3}$ ao argumentarmos que a acusação do uso de forças do oculto na obtenção e acumulação de riqueza nas comunidades por parte de alguns dos seus membros, tem uma relação directa com a luta destas para evitar internamente a diferenciação 
económica, eliminar as clivagens criadas por classes económicas distintas e manter assim o necessário nivelamento propiciador de um ambiente de equilíbrio social. ${ }^{4}$

\section{0 debate sobre a economia moral e a economia de afeição}

O conceito de «economia moral» defende a ideia que a actividade económica campesina, fundamentalmente as relações de produção e distribuição, está envolvida e é moldada pelas relações e comportamentos sociais compartilhados dos camponeses.

O termo «economia moral» foi introduzido no discurso académico por Edward Palmer Thompson, que estudou as rebeliões por pão das multidões inglesas no século XVIII, e que o usou para descrever um tipo de economia que o povo pretendia reimpôr contra a economia livre de mercado do início da Europa capitalista, porque «[...] ensinava ser imoral qualquer método desonesto de aumentar o preço dos alimentos para se aproveitar das necessidades do povo» (2004: 66).

6 Esse conceito, por sua vez, inspirou James Scott que, ao analisar as razões que levaram a população do Vietname central, nos anos trinta do século passado, a rebelar-se por alimentos, considerou que essa revolta pode ser entendida pela economia moral, ou seja, a noção de justiça económica da população e as suas definições de exploração no trabalho. Scott defendia também que o camponês mantém uma "ética de subsistência» por meio de um comportamento de aversão ao risco, pois relativamente às tomadas de decisão, o seu comportamento é de aversão ao risco, ao minimizar a probabilidade subjectiva da perda máxima (1976: 3-4).

7 Antes ainda de Thompson e Scott, Karl Polanyi havia já elaborado o conceito de «imbuição» das instituições económicas, que defendia que os elementos da economia estão imbuídos em instituições não económicas e que o próprio processo económico está institucionalizado pelo parentesco, casamento e grupos de idade (1957: 70). Polanyi punha assim em discussão a importância dos modelos de mercado ocidentais para as economias menos desenvolvidas, diferenciando desse modo as economias capitalistas modernas baseadas nos mercados autorregulados, das economias tradicionais, onde as relações de produção e troca estão imbuídas em regras e práticas sociais muito mais abrangentes (DOGAN 2010: 4; AUSTEN 1993: 93).

Mas o comportamento económico tradicional foi também analisado por George Foster e Edward Banfield. Foster defendia que os camponeses experienciam um mundo do «bem limitado", já que a sua existência é determinada e limitada pelos recursos existentes à sua volta e que apenas conseguem melhorar a sua posição social à custa dos outros (1965: 297). Banfield por sua vez, argumentava que o atraso tecnológico e social dos camponeses, se deve em parte a um «familismo amoral», ou seja, à sua inabilidade para agir em conjunto para um bem comum, desde que esse bem transcenda o interesse material da família nuclear (1958: 10). Resulta assim que, de acordo com Austen (1993: 92), as tentativas de definição teórica da economia moral têm tido por base a oposição entre o indivíduo maximizador que, por um lado, se pretende afirmar numa economia capitalista em expansão e, por outro, a comunidade regida por normas de sobrevivência colectiva e que identifica essas acções maximizadoras como feitiçaria. Essa oposição traduz o pensamento africano que entende a acumulação de riqueza como uma acção perigosa e de apropriação por parte de indivíduos egoístas dos recursos reprodutivos 
limitados das comunidades, defendendo desse modo um universo de soma-zero. Este conceito corresponde, pois, ao comportamento humano que resulta da suposição de que todo bem numa comunidade é limitado em quantidade, pelo que, qualquer porção retirada desse bem implica que haverá menos para ser usado, o que leva os membros da comunidade a impedir que acções extrativas tenham lugar (AUSTEN 1993: 92; BENNET 1966: 206).

9 O conceito de «economia de afeição», por seu lado, foi criado por Goran Hayden, que defende que as unidades de produção agrícola em África são autónomas e orientadas para a subsistência. Como os camponeses têm laços emocionais com os seus parentes e amigos, que estão prontos para auxiliá-los materialmente em ocasiões de infortúnio, essa rede de apoio e interacção, baseada na troca recíproca, ou economia de afeição, do mesmo modo que os ajuda a assegurar a sua subsistência, concomitantemente, também contribui para a sua exclusão do mundo moderno do capitalismo, que falha em «capturá-los» e em modernizar os seus sistemas de produção (TSURUTA 2008: 35).

10 Mas todas essas análises desenvolvidas sobre os conceitos de economia moral e economia de afeição sofreram críticas. As análises de Scott foram criticadas por negligenciar as capacidades empreendedoras dos camponeses com vista à obtenção de lucro. Scott reconheceu posteriormente que essas análises tinham sido bastante abstractas, pois, as novas perspectivas sobre as necessidades das famílias camponesas modernas já não entendem essas necessidades como de sobrevivência, nem o seu comportamento é considerado de aversão ao risco. Isso deve-se ao facto de haver actualmente uma completa imersão das economias tradicionais nos meandros dos mercados capitalistas e essas famílias necessariamente calculam os riscos que se predispõem a correr (AUSTEN 1993: 93). Do mesmo modo, as análises de Polanyi sobre a componente moral das trocas comerciais nos países menos desenvolvidos foram criticadas por mostrar uma abordagem demasiado etnocêntrica.

11 Mas, por outro lado, o conceito de «imbuição», de como os mercados podem ser imbuídos em instituições não-económicas, e as suas análises sobre os aspectos da reciprocidade e redistribuição como transacções de carácter não-económico, ou as suas conclusões de que o modelo de economia formal com os indivíduos a maximizarem ganhos económicos por meio de comportamentos competitivos não se aplicar a todas as sociedades, podem ajudar a analisar as relações entre as aquisições individuais e a feitiçaria em África (AUSTEN 1993: 93; VINHA 2003: 209).

12 Também Foster e Banfield sofreram críticas aos seus trabalhos por as suas análises ao comportamento dos camponeses indicarem verdadeiros obstáculos ao progresso e à coesão social, mas sem levarem em conta que os mesmos são adoptados pelos camponeses porque estes são explorados ou são confrontados com situações que os forçam a adoptar esses mesmos comportamentos (AUSTEN 1993: 93; BENNET 1966: 206-210). Por sua vez, Hayden foi criticado por considerar que os camponeses africanos ainda não foram «capturados» pelo capitalismo, já que, pelo contrário, actualmente é evidente uma monetarização das transações camponesas o que obviamente reduz grandemente a importância da componente de subsistência na economia tradicional, mas sem contudo a eliminar (SUGIMURA 2007: 4).

13 Os dois conceitos apresentam similitudes e dissimilitudes, já que as análises desenvolvidas principalmente por Scott e Hayden, cobriram diferentes contextos nomeadamente o asiático e o africano. Mas apesar de ambos os conceitos sublinharem a ligação indivisível que há entre a economia de subsistência dos camponeses e os 
imperativos morais a ela subjacentes, na Ásia, a economia moral nas relações interpessoais é fundamentalmente baseada em preocupações seculares como a reciprocidade generalizada, enquanto em África, por outro lado, a economia de afeição pode ser determinada pela feitiçaria. Ou seja, a reciprocidade na Ásia tem uma verdadeira base moral enquanto em África, ela poderá estar associada ao medo de retaliações por falta de retribuição. Como tal, a obrigação de intercambiar produtos funciona como um mecanismo nivelador, que apesar de contribuir para a redução da insegurança na adversidade, por outro lado, é impeditivo das ambições do camponês para a expansão da produção e consequente acumulação de riqueza (TSURUTA 2008: 45).

14 Em absoluto, tanto o conceito de economia moral como o de economia de afeição têm as suas lacunas, mas é importante sublinhar que ambos servem para analisar questões que o pensamento ocidental não prestou atenção nas economias do mundo subdesenvolvido, como a dimensão cultural do capitalismo. Particularmente, o conceito de economia de afeição deu um importante contributo à compreensão da realidade africana. Em suma, ambas teorias enfatizam obrigações morais culturalmente induzidas e imbuídas na economia de subsistência do camponês (TSURUTA 2008: 50).

\section{A mayombola como força do oculto}

A mais antiga referência escrita sobre actividades sobrenaturais que pudessem ser entendidas como mayombola foram as descritas no século XVII pelo Padre Cavazzi de Monteccúcollo, que retratou a existência de um feiticeiro entre os Ndongo, que se chamava nganga-mbungula, que «só com o assobio atrai a si qualquer pessoa que lhe aprouver, de maneira que, guardando-a como propriedade sua, a tem como escrava e a pode vender a outros», ${ }^{5}$ algo tão inverosímil para o prelado que lhe pareceu «incrível tal malefício», pelo que não sabia «explicá-lo convenientemente» (I, 1965: 98). Segundo Ribas (2009: 25 158), a mayombola «é magia para o aproveitamento da alma» passando esta a «trabalhar em lavouras humanas, durante alguns anos, como que cumprindo um contrato». Para Chicoadão (2005: 100) a mayombola é o «processo que permite a um indivíduo, em estado físico normal, entrar em estado de bilocação [...]», ou seja, «[...] o indivíduo transfigura-se, passando da vida real para a vida mística, irreal, do além», mas "as pessoas iyomboladas ou kamutukulenizadas mantêm a forma física humana e neste estado físico prestam serviço ao seu senhor», um estado que se chama «yipa». Milando (2013: 72) observa que a população de Cabinda acredita na existência de uma "entidade material dotada de poder de ubiquidade», denominada ndoki, que, por norma, durante o dia é uma pessoa normal, mas que durante a noite abandona o seu leito para exercer práticas ocultas maléficas. 0 ndoki «tem igualmente a capacidade de sujeitar as suas vítimas a trabalhos forçados, enquanto dormem, sem que disto tenham consciência mas sofrendo diariamente de fadiga muscular, como consequência do esforço físico [nocturno] empreendido». Esta descrição conforma pois um quadro de mayombola.

16 As entrevistas por nós conduzidas mostraram, entretanto, que a crença na mayombola apresenta detalhes diferenciados na sua descrição. É normalmente relatada como o uso da alma de quem sofre a mayombola, que é transferida para a lavra de quem a executou onde é usada para o trabalho escravo. Aos olhos dos outros, as pessoas «mayomboladas» tornam-se invisíveis, mas circulam normalmente pelas comunidades, podendo até frequentar mercados e festas sem serem reconhecidos e detectados. Desse modo, a 
pessoa que sofre a mayombola, continua viva, mas entra num estado de entorpecimento, de cansaço contínuo com posterior emagrecimento, resultado do esforço físico realizado pela sua alma, que é acorrentada para trabalhar na lavoura durante a noite e que pode ser libertada findo o prazo de escravidão. 0 indivíduo «mayombolado», ao acordar pela manhã sente-se demasiado cansado sem razão aparente, mas tal se deve ao facto de a sua alma ter estado a trabalhar durante a noite. Outros relatos indicam que determinados indivíduos são mortos por feiticeiros por meios ocultos a mando de alguém para utilizar a sua alma para os mesmos fins, podendo essa morte ser provocada por diferentes animais, que são enviados para os matar (LOPES 2005: 26). ${ }^{6}$ Depois de enterrado o corpo, o feiticeiro acompanhado de ajudantes, durante a noite, prostra-se sobre a sepultura e «ao som de batuque e de canção, vai fazendo batimentos sobre a terra» e, ao longo da cerimónia, «o féretro vai subindo a cada batimento, até sair do sepulcro», ficando a alma deste defunto «ad aeternum, ao serviço daquele que o iyombolou, melhor, daquele que The provocou a morte» sendo depois levada para o «luwanda» (ganda) local de culto dos feiticeiros (CHICOADÃO 2005: 38). ${ }^{7}$ As almas dos indivíduos «mayombolados» podem ainda ser encarceradas em morros de salalé (luyila). ${ }^{8}$

Esses relatos, realçam também que os feiticeiros são mesmo capazes de ocultar os corpos das suas vítimas retirando-os dos sepulcros e substituindo-os por troncos de bananeiras. ${ }^{9}$ Importa destacar que uma característica comum relatada para todos os casos de mayombola é o facto de que a pessoa responsável por ela ser sempre alguém próximo da vítima, algo que se explica por os familiares partilharem bens comuns através dos quais é a mesma transmitida. Por outro lado, o indivíduo que sofre a mayombola pode ser recuperado do seu estado de escravidão por meio de certo tratamento específico (kiteke), seguindo determinados rituais, que deve ser realizado por um médico tradicional especializado, no qual o seu funeral é encenado, cavando-se uma campa onde se enterra uma figura com as suas características, acompanhada de alimentos e colocando-se por cima notas em dinheiro para a pessoa que as apanhar, levar consigo os efeitos da mayombola..$^{10}$ Outra cerimónia, que inclui o chamamento do indivíduo «mayombolado» junto da nascente de um rio, também é usada para a sua recuperação. Mas essa recuperação tem necessariamente que ter a colaboração do acusado e da família do indivíduo «mayombolado». Os relatos referem ainda que há aldeias inteiras de pessoas «mayomboladas» nas florestas e nas montanhas, que mantêm uma vida normal, comendo, bebendo, dançando e até casando, mas é frequente elas queixarem-se de fome e das difíceis condições em que trabalham, por meio de choros e lamentos, que se ouvem durante a noite ou quando aparecem às pessoas em determinados ritos de possessão ${ }^{11}$ (RIBAS 2009: 25). Na província do Kwandu-Kuvangu, quando foram detectados os casos de kamutukuleni, a população afirmava ter cruzado com pessoas já falecidas a circularem pelas aldeias, que lhes pediam de comer por terem muita fome (CHICOADÃO 2005: 167).

\section{A mayombola como arte sobrenatural de enriquecimento}

18 De acordo com os entrevistados para a realização deste trabalho, a força escrava sobrenatural obtida por meio da mayombola, tem sido usada ao longo dos tempos para o enriquecimento de muitas pessoas, pelo que analisamos especificamente o caso particular da região norte do país, onde os produtores de café nativos dela se serviam 
para aprisionar pessoas para serem usadas posteriormente nas plantações e assim aumentar as suas colheitas.

19 Os primeiros passos na expansão da produção do café nas áreas de Cazengo, GolungoAlto e Ambaca e na zona Dembos-Uíje, nas províncias do Kwanza Norte, Bengo e Uíje, foram dados a partir de 1930 e as explorações europeias de café bem sucedidas, estimularam os africanos a dedicar-se ao seu cultivo, entre os quais se encontravam chefes políticos e membros da aristocracia tradicional local (FREUDENTHAL 2005: 166-179).

20 No período 1950-1966, houve um aumento médio do volume de produção do café de cerca de $11 \%$, o que mostrava uma tendência de crescimento devido também, em grande parte, ao trabalho desenvolvido nas lavras dos camponeses nativos (DILOLWA 1978: 229). Em 1950-1954, quando se dá o boom das cotações do café como resultado da guerra da Coreia, a adopção mais alargada do cultivo do café pelos camponeses nativos e os consequentes rendimentos obtidos, que incentivaram a monetarização das economias locais, produziu desigualdades económicas visíveis entre os produtores tradicionais e os que mais tardiamente se integraram no processo de produção de café. Nesse período, o consumo de artigos diferenciados, que não faziam parte do quotidiano dos camponeses, tornou-se a imagem de modernidade. Para os camponeses produtores de café que viviam num ambiente deveras competitivo e cujos rendimentos eram diluídos numa interminável cadeia de intermediários que «iam açambarcando as partes da mais-valia» (DILOLWA 1978: 230), evidências de riqueza materializadas pelo consumo de artigos de importação, pareceram, pois, aos olhos dos nativos, inexplicáveis.

Desse modo, disseminavam-se os discursos feiticistas que mostravam o descontentamento dos camponeses com novas formas de enriquecimento, que eram entendidas como sendo obtidas com recurso a forças ocultas. Tais discursos procuravam assim explicações com base num tipo diferente de feitiço em que os feiticeiros eram capazes de roubar a alma das suas vítimas e transformá-las em trabalhadores-escravos dos camponeses mais ricos, mantendo as pessoas num estado de dormência enquanto as suas almas serviam quem as aprisionava. Observa-se, assim, nas comunidades cafeícolas, dificuldades acrescidas de lidar com uma situação de tensão social criada por um novo contexto de mudanças económicas, num universo prevalecente de soma-zero. Neste universo, a riqueza adquirida pelos membros mais ricos da comunidade deve ser distribuída por todos, por diferentes meios, como os empréstimos, o patrocínio para óbitos e outras actividades sociais, ou a criação de relações de clientelismo com os menos afortunados. Como a criação de riqueza é vista pela comunidade como um perigo para todos, pois a diferenciação económica criada pode pôr em perigo a sua estabilidade social, tipos informais de sanções como as acusações de recurso ao oculto surgem imediatamente para repôr o equilíbrio. Desse modo, qualquer forma individual de sucesso económico, que não tenha sido obtido em cooperação e que não tenha também sido compartilhada como resultado do controlo social exercido pela comunidade, para quem a generosidade é uma regra social capital, cria prontamente a suspeição de feitiçaria (MALUMBU 2005: 259; CHILDS 1949: 56-57). As comunidades têm, pois, no seu interior «indivíduos que importa não distinguir através de tratamentos diferenciados; qualquer tentativa de introduzir entre eles o mínimo traço diferencial será imediatamente imputada às maquinações da feitiçaria» (SILVA 1989: 114). limitações à livre circulação de pessoas e bens, provocou o regresso do campo «à auto 
subsistência em consequência da ruptura dos circuitos comerciais» e transformou o sector informal no «sector esponja» que absorveu grande parte da população economicamente activa empregada nos meios urbanos (NZATUZOLA 2005: 59). O desenvolvimento económico de muitas zonas do país ficou limitado, o que eliminou consequentemente as possibilidades do surgimento de iniciativas individuais de criação de riqueza, provocando desse modo o empobrecimento de grande parte da população. Com a abertura democrática que se verificou posteriormente, a abrupta conversão do regime económico de orientação socialista prevalecente para uma economia de mercado operou-se sem «uma forma moderna de capitalismo, com mecanismos de mercado eficazes que promovessem uma concorrência leal e protegessem os interesses sociais nacionais», pelo que, «o abandono do marxismo-leninismo deu lugar a um vazio filosófico e mesmo moral em que deixou de haver qualquer sentido de obrigação social ou solidariedade» e «o ethos do capitalismo selvagem criou formas extremas de venalidade no seio da elite, contribuindo para um forte sentimento de decadência moral ou de crise de valores na sociedade» (HODGES 2002: 71). 0 empobrecimento da população «deu-se em paralelo com a ascensão de uma elite abastada, uma situação que resultou numa maior estratificação social e numa maior desigualdade» (HODGES 2002: 65). Assim, as condições resultantes do novo contexto socioeconómico fizeram com que as oportunidades de enriquecimento ficassem restritas a uma minoria, levando as populações ao longo dos anos a serem consumidas pela frustração e a criar ressentimentos contra essas elites económicas recém-nascidas. De um momento para o outro, sem que se tenha verificado um passado aparente de trabalho árduo, muitas pessoas tornaram-se milionárias, personificando assim o triunfo da nova era capitalista. Porém, esse enriquecimento suscitou perplexidade e estranheza. Essa criação e afirmação de riqueza sem uma produção perceptível e com ganhos sem ligações a esforços pessoais visíveis, provocou, desse modo, a busca de explicações fora do convencional. Os rumores sobre o uso da mayombola para acumular riqueza ganharam então mais força e passaram a explicar o sucesso dos novos-ricos e a consequente diferenciação económica que se passou a verificar. Para a população essa acumulação enigmática era imoral, pelo que, partia do princípio de que as pessoas mais abastadas tinham «mayombolado» os seus familiares, que tinham aparentemente falecido, para usá-los como força de trabalho escravo para terem sucesso nos seus negócios.

A ameaça imaginária da mayombola é assim estimulada por sentimentos de desassossego e ansiedade e as respostas encontradas não proporcionam satisfação emocional, pois essa prática parece correr contra o curso normal da vida das pessoas. Desse modo, a crença na mayombola ajuda a conservar um universo moral, que inclui determinadas funções normativas e educativas. Os casos específicos de ocorrência de mayombola nas províncias do Kwandu-Kuvangu e Zaire são assim exemplificadores de que o chamamento para a riqueza material por meios insondáveis foi tomando conta das mentes populares motivando por isso o recurso ao oculto como forma de obtê-la, pelo que, esses casos tinham necessariamente circunstâncias económicas como seu denominador comum. No Kwandu-Kuvangu, um dos acusados de fazer uso do kamutukuleni foi João Lucas Tchiovo que, aquando de uma deslocação para negócios, contactou «para fazer bom negócio [...] o velho Sá-Tchicanda Fulai Chizoca que tem muitos sistemas de magia, para contrair a sorte» (CHICOADÃO 2005: 165). Na província do Zaire, Fernando Alberto Isabel e a sua esposa Inês João Maria, também com a intenção de ganharem dinheiro, pretendiam fazer crer que o seu filho Samuel João Inês, falecido no ano anterior, tinha sido vítima de mayombola e que havia ressuscitado, tendo voltado 
para o convívio dos seus. Para o efeito, apresentaram como seu filho ressuscitado o jovem Makubama Beka, de nacionalidade zairense, que se fazia passar por Samuel Inês, que por ter um determinado sinal físico que relembrava o falecido, o usavam como forma de sustentar a farsa da ressurreição. A intenção era criar uma igreja onde a ideia de que a mesma seria capaz de realizar milagres, poderia potenciar o aumento do número de crentes e consequentemente o elevar das receitas. ${ }^{12}$ Os dois casos mostram assim, uma intenção deliberada de tentar obter sucesso económico com recurso a forças ocultas.

As pessoas, ao viverem em comunidade é suposto não entrarem em contradição, mas sim ajudarem-se umas às outras, sobrevivendo em conjunto para atingir objectivos $\mathrm{e}$ defender interesses comuns, mantendo para o efeito códigos internos de lealdade. Quando alguém tem um comportamento ofensivo, esse comportamento é entendido como ofensivo para todos. Se essa pessoa faz recurso à mayombola, tentando açambarcar os escassos recursos da comunidade, está a pôr em risco a unidade do grupo e a minar a lealdade existente, colocando assim em perigo valores preservados por todos e ultrajando os mais sagrados sentimentos sobre os quais assenta a moral social. Desse modo, tal comportamento tem que ser condenado, o que determina a ruptura com o acusado de uso de mayombola. Esta acusação é assim uma catarse que purga a comunidade toda de determinadas ansiedades, preocupações e medos relativamente à distribuição de riqueza. A comunidade encontra assim um responsável pelos problemas económicos que a assolam (MAYER 1954: 55).

\section{A mayombola e a sua ligação com o poder tradicional}

Apesar de os casos de mayombola relatados terem uma forte e envolvente característica económica, encerram em si também aspectos de poder a nível comunitário. Esse poder é exercido principalmente pelos anciãos. Nas aldeias, em ambientes de nítido empobrecimento, possuir dinheiro significa possuir poder. Por esse motivo, a acumulação desmedida de riqueza é uma das práticas a que os anciãos de cada comunidade mais se opõem porque minam a sua autoridade e poder e interferem na coesão social das próprias comunidades. Num meio social onde a solidariedade e o compartilhar contam bastante e onde há uma linha demarcada de autoridade e de obediência, quando surgem pessoas cujas atitudes são capazes de abalar as condições existentes, imediatamente, são accionados mecanismos internos de defesa para evitar roturas que periguem os poderes instituídos.

As acusações de manipulação de forças ocultas constitui um desses mecanismos e a reposição do equilíbrio social desfeito, é incitado pelos anciãos. Nos dois casos analisados, questões de poder também estiveram na base das acusações de uso de mayombola. No Kwandu-Kuvangu, município do Kwitu-Kwanavale, onde ocorreu o caso de kamutukuleni, o soberano do Kwitu-Kwanavale, Mwene Txhisasa Bingo-Bingo, nomeou uma comissão para o investigar, composta por vários anciãos da sua territorialidade, que concluiu que a atitude tomada por Lucas Tchiovo mostrava desrespeito «ao soba perante o povo» e aos membros do grupo do rei por «desconseguir de descobrir todo o segredo» que tinha sobre a mayombola aos mesmos, segredo esse que ele mantinha "com os feiticeiros grandes». Os membros do grupo do soberano também se sentiram defraudados por «não haver ninguém da parte do Rei uma pessoa com este segredo" (CHICOADÃO 2005: 168). As conclusões do inquérito mostraram pois um 
evidente ressentimento por parte do grupo do soberano, pessoas colocadas ao mais alto nível na hierarquia da territorialidade, que reconheceu não ter os fortes poderes aparentemente absorvidos pelo acusado, o que despoletou a necessidade de puni-lo numa forma gerontocrática de controlo social e de afirmação de poder. Do mesmo modo, um outro utilizador de kamutukuleni, o Soba Tchivava, Sakahili ka Dumba, foi também acusado de que "retém pessoas que se pensa estarem mortos no sobi onde ele pretende organizar uma nova aldeia» (CHICOADÃO 2005: 180). Esta acusação surge assim, também, como uma forma de acautelar quebras de poder, para impedir a pulverização do poder mantido pelo soberano, que poderia eventualmente ser afectado pela criação de uma nova aldeia. No caso do Soyo (província do Zaire), os anciãos locais quando tomaram conhecimento das intenções do casal, que indiciavam uma forma não aceitável de acumulação, sentiram a necessidade de preservar o nivelamento social existente na aldeia, pelo que, se opuseram aos seus intentos e promoveram a destruição do mito criado.

No passado, determinadas elites políticas tradicionais munidas de poderes espirituais eram responsáveis pelo bem-estar social das comunidades, controlando o comércio com as comunidades vizinhas, a distribuição das terras e o acesso às áreas de caça e pesca, influenciando assim a acumulação e o sucesso económico dos grupos familiares nas aldeias. Os poderes sobrenaturais que anunciavam possuir permitiam a essas elites, proporcionar riqueza aos membros das comunidades, que era apenas baseada na acumulação controlada de bens geridos por si e em nome dos grupos familiares. Como resultado da rápida expansão capitalista e com a criação de valor baseado no dinheiro, surgiram novas formas de acumulação com características mais individualistas. Como a acumulação individual choca com a posse dos grupos, e reduz a importância das elites na administração da riqueza, de forma a manter o controlo exercido, estas atribuíram características maléficas a essas novas formas de acumulação. Como é da responsabilidade das elites a determinação da periculosidade das manifestações sobrenaturais, desse modo, tinham elas uma forma prática de controlar manifestações de riqueza, condenando ou apoiando iniciativas individuais de acumulação conforme os seus interesses práticos.

o poder gerontocrático é, assim, responsável pela manutenção de um universo de soma-zero. Algumas das pessoas por nós entrevistadas observaram que muitos casos de mayombola têm lugar, sancionados pelas altas estruturas hierárquicas das comunidades, havendo mesmo chefes e outros responsáveis comunitários que também o praticam. É assim que muitos desses casos não são do conhecimento público ou esses responsáveis criam condições para que tais casos não provoquem a atenção das comunidades fazendo arranjos internos com as famílias atingidas por meio de compensações diferenciadas. Apenas quando esses casos fogem do controlo das estruturas locais de poder é que são imediatamente associados ao mal e se procede à sua eliminação, mas enquanto tiverem ligações às elites são legitimados, protegendo-se assim novas formas de acumulação devidamente salvaguardadas. ${ }^{13}$

\section{A mercantilização da mayombola}

29 A mayombola apenas pode ser preparada por um feiticeiro pelo que, este tem que ser necessariamente consultado por quem pretender exercê-la sobre outrem, o que determina a existência de um mercado para tal fim. 
30 De acordo com os médicos tradicionais por nós entrevistados, ainda há muitos feiticeiros «mayomboladores» que contactados por diferentes pessoas que pretendem «mayombolar» um familiar, aproveitam-se dos seus corpos para lhes retirar as almas e vendê-las para trabalho escravo. A mayombola é ainda usada por muitos produtores agrícolas para aumentar os valores da produção das suas áreas cultivadas, ${ }^{14}$ mas, especificamente para a região norte do país, com o declínio da produção de café, os casos de mayombola sofreram também uma redução acentuada circunscrevendo-se actualmente apenas ao círculo mercantil informal. Nestes círculos, as mulheres comerciantes servem-se do trabalho de pessoas «mayomboladas» compradas aos feiticeiros, para impedir as receitas das concorrentes, que apesar de venderem os seus artigos não obtêm dinheiro nenhum, impedidas pelas «mayombolas». De acordo com os nossos entrevistados, há muitos anos atrás, a mayombola era apenas praticada por anciãos reunidos em sociedades secretas, a que muitos poucos tinham acesso e que exigia rituais específicos para a filiação. As pessoas «mayomboladas» serviam então como «instrumentos de trabalho» dos membros dessas sociedades para a resolução de situações de negócios pontuais. A mayombola não era de forma nenhuma comercializada. Mas, actualmente, como resultado de uma economia menos baseada na força de trabalho braçal, com o declínio da produção doméstica, com o aumento do trabalho remunerado em dinheiro e com a vida cada vez mais exigente em termos materiais num mundo abertamente industrializado e voltado para o consumo, a mayombola vulgarizou-se, «democratizou-se» (ROSNY 1981: 116). ${ }^{15}$ Os meandros secretos da mayombola foram-se tornando conhecidos por muitos pelo que passou a ser um produto comercializável. A compra dos indivíduos «mayombolados», é também muitas vezes feita fora das áreas geográficas de onde são originários os seus mentores como uma forma de manter a descrição e evitar interferências inoportunas para o negócio pelo que essas pessoas ao serem levadas para muito longe das suas terras de origem podem, a maior parte das vezes, nunca mais regressar. A tomada de consciência de muitas pessoas quanto à sua marginalização em relação à distribuição de riqueza faz com que tentem participar nessa distribuição com os meios a sua disposição, uma vontade que é então fortemente conduzida pelos exemplos de fortunas obtidas com recurso ao oculto. Por essa razão, o mercado da mayombola é constantemente alimentado pela vontade individual de se ter acesso a formas de acumulação por meios sobrenaturais. Ao estarem inseridas num mundo modernizado e industrializado onde tudo é susceptível de ser comercializado e onde até a vida humana se encontra dependente dos caprichos do mercado livre, o mercado da mayombola é para as pessoas um escape para uma utópica obtenção de riqueza.

\section{Reflexões gerais sobre a mayombola}

Os relatos feitos pelos entrevistados sobre a mayombola, que não obstante se mostrem aparentemente ambíguos e inconsistentes, têm para a população a devida coerência e a precária distinção que fazem sobre determinados aspectos característicos do fenómeno, não reduzem, contudo, a crença na sua existência. Torna-se assim evidente, que a preocupação geral com a mayombola é com a sua eficácia e a sua aplicação geográfica, pois pode atingir qualquer um.

Para a população, esse tipo particular de feitiço existe de facto e é usado para prejudicar certas pessoas. Tais discursos que parecem aberrações, falaciosos e mesmo 
inverosímeis aos olhos do mundo científico, colocados no seu contexto não o são porque há de parte das populações uma crença declarada na existência de forças ocultas capazes de transformar pessoas em mortos-vivos. Tais eventos são mesmo considerados normais na sua vida quotidiana, constituindo por isso uma realidade nos seus sistemas sociais.

Para a população, as forças do oculto para se aproveitarem das fraquezas humanas estão sempre em permanente mutação e constantemente a inovar-se para refinar as suas características maléficas. Por isso, não é importante como se apresentam, mas sim como actuam e os efeitos nefastos que produzem. A crença na mayombola tem necessariamente ligação com algo real na experiência humana, pois ao ocorrer nos mais diferentes lugares, tempos e níveis culturais, não pode ser simplesmente rejeitada como uma criação despropositada da fantasia humana. O poder da mayombola por si só é seguramente imaginário, mas o poder dessa ideia por norma inspira as pessoas a defender-se e a contra-atacar. A busca da realidade básica subjacente à crença na mayombola deve assim nortear o seu entendimento. E essa realidade é uma realidade não-física mas social, já que, esse fenómeno constitui uma resposta a ansiedades, medos e tensões sociais, de quem nele acredita (MAYER 1954: 55).

A análise dos discursos sobre a mayombola só tem sentido de acordo com cosmovisões muito concretas que nem sempre são coerentes, seguindo o sistema de pensamento científico, pelo que, é necessário ter em conta que quando analisamos tais discursos mesmo que façamos o seu enquadramento no domínio da irracionalidade, esta, apesar de tudo, não deixa de ser parte da nossa existência (MARTí 2011: 8). A crença na mayombola pode parecer irracional porque pressupõe relações causais que não podem ser provadas (ou desaprovadas), mas, por outro lado, é também racional tanto quanto fornece respostas internamente consistentes e logicamente induzidas de premissas aceitáveis. Essa crença pode não ser conscientemente racional mas também não é totalmente contrária à razão (WILSON 1951: 275).

A mayombola deve ser pois entendida «não como uma distante imaginação [...] mas como uma realidade estruturante das racionalidades» das populações e «uma das expressões da extrema complexidade das sociedades agrárias africanas» (MILANDO 2013: 91-92). Por isso é extremamente difícil entender os relatos sobre a mayombola seguindo estritamente a dualidade realidade/fiç̧ão, já que, essa dicotomia em determinados contextos precisa de ser relativizada. Julgar o imaginário com padrões racionais pode não produzir efeitos concretos (MARTí 2011: 8).

Para a população em muitas situações do seu quotidiano, não há uma distinção clara entre o que é real e o que é imaginário, e a compreensão que os habitantes das comunidades têm dos seus modos de estar e de ser vagueia entre um mundo real e palpável e um mundo irreal, imaginário, que apesar de não poder ser visto é seguramente sentido e influencia realmente o mundo presente em que vivem. Desse modo, é importante problematizar os discursos sobre a mayombola, contextualizando-os para compreender sob que circunstâncias as pessoas a eles se referem e neles acreditam e que efeitos têm na sua vida quotidiana. Isto significa entender tais discursos, os rumores criados à sua volta e tentar encontrar explicações para contextos específicos, identificando para o efeito os momentos em que tais discursos se traduzem em acções concretas (GESCHIERE 1997: 21-22). 


\section{Conclusões}

37 Os nossos argumentos de que as acusações de recurso ao oculto para a acumulação de riqueza são explicadas pela luta desencadeada pelas comunidades para preservar internamente a igualdade económica e evitar desnivelamentos sociais, são teoricamente comprovados pelas análises feitas aos discursos sobre a mayombola em várias províncias do país. Essas análises, mostram que o conceito de mayombola em Angola está abertamente ligado à crença de que a produção de novas riquezas depende da apropriação dos escassos recursos dos outros fazendo uso de forças externas sobrenaturais. Os actuais ambientes de empobrecimento no país resultantes de um contexto socioeconómico diferente, caracterizado por um capitalismo desumano, de onde sobressaíram concomitantemente elites abastadas com recursos ilimitados de proveniência desconhecida, explicam as acusações do uso da mayombola por parte de determinados indivíduos que enriqueceram por formas menos claras.

Tal crença, deve-se fundamentalmente à ligação indivisível que há entre a economia dos camponeses e os imperativos morais a ela ligados. Por essa razão, a crença nos efeitos da mayombola mostra a necessidade de a actual ordem capitalista ter que se submeter à, até agora de certa forma ignorada, componente moral da economia. Os discursos sobre a mayombola são bastante flexíveis e dinâmicos e indicam uma profunda imaginação colectiva sobre o quotidiano das populações, pelo que, tal crença não deve ser vista como um sinal de atraso cultural e subdesenvolvimento, nem a sua existência deve ser ignorada. A sua relevância social é enorme, pois como parte das racionalidades localmente dominantes, imerge profundamente no significado dos infortúnios e das desgraças humanas e determina comportamentos e atitudes perante as dificuldades que a vida impõe às populações (WINTER 2004: 216; SANDERS 2001: 179).

A mayombola é uma resposta às tensões sociais existentes nas comunidades e quanto mais formos capazes de identificar essas tensões, mais facilmente também encontraremos respostas para essa crença. Ao invés de se negar a sua existência, de a subalternizar ou mesmo de reduzir a sua importância, deverá ser analisada independentemente das suas características reais ou imaginárias e dissecada a sua dimensão cultural para que se encontrem soluções viáveis, que ajudem as populações a lidarem de forma menos dolorosa com esse medo quotidiano e com a consequente ansiedade de poderem vir a tornar-se também potenciais vítimas.

\section{BIBLIOGRAFIA}

ABRANCHES Henrique, 1980, Reflexões sobre a Cultura Nacional. Luanda, União dos Escritores Angolanos.

ALTUNA Padre Raul Ruiz de Asúa, 1985, Cultura tradicional Banto. Apresentação de Dom Eduardo André Muaca. Prefácio do autor. Luanda, Secretariado Arquidiocesano de Pastoral.

AUGÉ Marc, 1974, A construção do mundo. Lisboa, Edições 70. 
AUSTEN Ralph A., 1993, «The moral economy of witchcraft: an essay in comparative history», in Jean e John Comaroff (eds.), Modernity and its malcontents: Ritual and power on postcolonial Africa. Chicago, The University of Chicago Press, pp. 89-110.

BANFIELD Edward, 1958, The moral basis of a backward society. Glencoe, Illinois, The Free Press. BEIDELMAN T. O., 2004, «Witchcraft in Ukaguru», in John Middleton e E. H. Winter (eds.), Witchcraft and sorcery in East Africa. Londres, Routledge Library Editions, pp. 66-67.

BENNET John W., 1966, «Further remarks on Foster "Image of limited good"», American Anthropologist, n. 68 , pp. 206-210.

BOYER Paul e NISSENBAUM Stephen, 1974, Salem possessed: The social origins of witchcraft. Cambridge, MA; Londres, The Harvard University Press.

CABIMBA Vanusa e MAVINGA João, 2014, «Jovem regressa dois anos após “morrer”: troca de cadáveres na morgue do hospital municipal pode estar na origem da insólita situação», Jornal de Angola (Luanda), 8 de Agosto.

CARVALHO Ruy Duarte, 1989, Ana a Manda: os filhos da rede. Lisboa, Instituto de Investigação Científica Tropical.

CHICOADÃO, 2005, As origens do fenómeno Kamutukuleni e o direito costumeiro ancestral angolense aplicável. Lisboa, Instituto Piaget.

CHILDS Gladwyn Murray, 1949, Umbundu kinship \& character. Londres, Oxford University Press. COMAROFF Jean e COMAROFF John, 1999a, «Occult economies and the violence of abstraction: Notes from the South African postcolony», American Ethnologist, vol. 26, n.ำ 2, pp. 279-303.

COMAROFF Jean e COMAROFF John, 1999b, «Alien-nation: Zombies, immigrants, and millennial

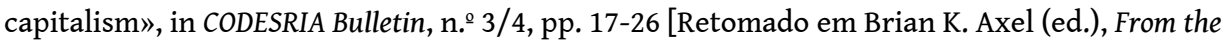
margins: Historical anthropology and its futures. Durham, NC, Duke University Press, 2001, pp. 267-302].

DILOLWA Carlos Rocha, 1978, Contribuição à história económica de Angola. Luanda, Imprensa Nacional de Angola.

DIOCESE DE MENONGUE, 1997, o mundo cultural dos Ganguelas: Estudos de Antropologia Cultural do povo Ganguela. Menongue, Secretariado de Pastoral da Diocese de Menongue.

DOGAN Mustafa G., 2010, «When neoliberalism confronts the moral economy of workers: The final spring of Turkish Labor Unions», European Journal of Turkish Studies, n..11, pp. 2-17.

DOMINGOS Antónia, 2012, Crianças vítimas de práticas de feitiçaria. Luanda, União dos Escritores Angolanos.

EVANS-PRITCHARD E. E., 2005, Bruxaria, oráculos e magia entre os Azande, Tradução de Eduardo Viveiros de Castro. Rio de Janeiro, Jorge Zahar Editor, [«Antropologia Social»].

FARIA António Lopes Coelho da Costa, 2004, 0 regresso da lavra da Maiombola. Luanda, Editorial Nzila.

FIGUEIREDO Jaquelino, 2014, «Morto ressuscitado: especialistas da DNIC investigam caso», Jornal de Angola (Luanda), 4 de Outubro.

FIGUEIREDO Jaquelino, 2014, 2014, «Caso polémico do Soyo: DNIC desmente história de suposta ressureição - jovem implicado no crime é de nacionalidade congolesa e alega ter sido persuadido», Jornal de Angola (Luanda), 18 de Outubro. 
FIGUEIREDO João de Castro Maia Veiga, 2011, «Feitiçaria na Angola oitocentista: Razões por detrás de uma suposta maior tolerância administrativa face a crenças locais», Revista de Humanidades da Universidade Federal do Rio Grande do Norte, vol. 11 (29), pp. 21-51.

FLORÊNCIO Fernando, 2010, «Pluralismo jurídico e estado local em Angola: Um olhar crítico a partir do estudo de caso do Bailundo», Antropologia Portuguesa (Coimbra), n.․ 28, pp. 95-134.

FOSTER George M., 1965, «Peasant society and the image of the limited good», American Anthropologist, n. ${ }^{\circ}$ 67, pp. 293-315.

FREUDENTHAL Aida, 2005, Arimos e fazendas: A transição agrária em Angola. Luanda, Edições Chá de Caxinde.

GESCHIERE Peter, 1997, The modernity of witchcraft: Politics and the occult in postcolonial Africa. Charlottesville e Londres, The University Press of Virginia.

GONÇALVES Jonuel, 2011, A economia ao longo da história de Angola. Luanda, Edicões Mayamba. HARRIS Patrick, 2005, Dead men working: A historical-anthropological look at the modern zombie phenomenon in Africa. Basel, University of Basel [«Ethnologisches seminar on the african occult»] HODGES Tony, 2002, Angola: do Afro-Stalinismo ao capitalismo selvagem. Lisboa, Edições Principia. KOHNERT Dirk, 2007, «On the articulation of witchcraft and modes of production among the

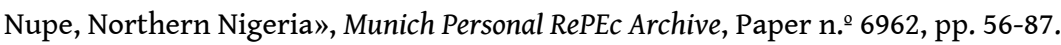

LAMBECK Michael, 1993, Knowledge and practice in Mayotte: Local discourses of Islam, sorcery, and spirit possession. Toronto, University of Toronto Press.

LOPES Luís Rosa, 2005, Mu ukulu, ki tuexilé ku mayombola. Luanda, União dos Escritores Angolanos.

MALUMBU Moisés, 2005, Os Ovimbundu de Angola: Tradição, economia e cultura organizativa. Roma, Edizione Vivere In.

MARTÍ Josep, 2011, «Witchcraft between tradition and modernity: The Ekongo case in Equatorial Guinea», The Scientific Journal of Humanistic Studies vol. 3, n.ํ5, pp. 1-11.

MARWICK Max, 1964, «Witchcraft as a social strain-gauge», Australian Journal of Science, n.․ 26, pp. 263-268.

MAYER Philip, 1954, Witches. Rhodes University, Grahamstown.

MILANDO João, 2013, Desenvolvimento e resiliência social em África: Dinâmicas rurais de CabindaAngola. Luanda, Mayamba Editora; Imprensa Nacional de Angola.

MONTECÚCCOLO Padre João António Cavazzi de, 1965, Descrição histórica dos três reinos do Congo, Matamba e Angola, 2 volumes. Lisboa, Junta de Investigações do Ultramar.

MURRAY Margaret A., 1952, The God of the witches. Oxford, Oxford University Press.

NEE Victor e INGRAM Paul, 1998, «Embeddedness and beyond: Institutions, exchange and social structure», in Mary C. Brinton e Victor Nee (eds.), The new institutionalism in Sociology, Stanford, Stanford University Press, pp. 19-45.

NIEHAUS Isak, 2001, Witchcraft, power and politics: Exploring the occult in the South African lowveld. Cape Town, Pluto Press.

NYAMNJOH Francis B., 2005, «Images of Nyongo amongst Bamenda Grassfields in whiteman kontri», Citizenship Studies, vol. 9, n. 3, pp. 241-269.

NZATUZOLA João Baptista Lukombo, 2005, População e mercado de trabalho em Angola: Alguns elementos essenciais e as suas incidências sobre o emprego em Luanda. Luanda, Editorial Nzila. 
OLSEN Wendy, 2005, «Moral political economy and poverty: Four theoretical schools compared», Global Poverty Research Group, Paper n.․․ 031, pp. 2-36.

POLANYI Karl, 1957, «Aristotle discovers the economy», in Karl Polanyi, Conrad Arensberg e Harry Pearson (eds.), Trade and market in the early empires: Economies in history and theory. Glencoe, Illinois, The Falcon's Wing Press, pp. 64-94.

RIBAS Óscar, 2009, Ilundo: Espíritos e Ritos Angolanos. Luanda, Edição do Ministério da Cultura.

ROCHA Manuel José Alves da, 2011, Alguns temas estruturantes da Economia Angolana. Luanda, Kilombelombe.

ROSNY Éric de, 1981, Les yeux de ma chèvre: Sur les pas des maîtres de la nuit en pays douala, Cameroun. Paris, Éditions Plon.

SANDERS Andrew, 1995, A deed without a name: The witch in society and history. Oxford, Berg Publishers Limited.

SANDERS Todd, 2001, «Save our skins: Structural adjustment, morality and the occult in Tanzania», in Todd Sanders e Henrietta L. Moore (eds.), Magical interpretations, material realities: Modernity, witchcraft and the occult in postcolonial Africa. Londres, Routledge, pp. 160-161.

SAVE THE CHILDREN, 2002, Estudo sobre as crianças em situação de risco nas províncias do Zaire, Uíje e Luanda. Relatório preliminar. Luanda, Save the Children [edição policopiada].

SCOTT C. James., 1976, The moral economy of the peasant: Rebellion and subsistence in Southeast Asia. New Haven e Londres, Yale University Press.

SILVA José Carlos Gomes da, 1989, A identidade roubada: Ensaios de Antropologia Social. Lisboa, Gradiva.

SUGIMURA Kazuhiko, 2007, «African peasants and moral economy», PEKEA Newsletter, n. 9, pp. $1-6$.

THOMPSON Edward P., 2004, A formação da classe operária inglesa. A árvore da liberdade, Volume I, Rio de Janeiro, Paz e Terra.

TSURUTA Tadasu, 2008, «Between moral economy and economy of affection», in I. N. Kimambo, G. Hayden, S. Maghimbi e K. Sugimura (eds.), Contemporary perspective on African moral economy. Dar es Salaam, Dar es Salaam University Press, pp. 35-54.

TURNER Victor W., 1957, Schism and continuity in an African society. Manchester, Manchester University Press.

VINHA Valeria, 2003, «Polanyi e a nova sociologia económica: uma aplicação contemporânea do conceito de enraizamento social», Revista Económica, vol. 3, n.․ 2, pp. 207-230.

WEST Harry G., 2009, Kupilikula: O poder e o invisível em Mueda, Moçambique. Lisboa, Instituto de Ciências Sociais da Universidade de Lisboa [«Imprensa de Ciências Sociais»].

WILSON Monica Hunter, 1951, «Witch-beliefs and social structure», American Journal of Sociology, n.ำ 56 , pp. 307-313.

WILLIS Roy, CHISANGA K., SIKAZUE, H., KAPEMBWA B. Skazue e NANYANGWE Sylvia, 1999, Some spirits heal, others only dance: Journey into human selfhood in an African village. Oxford, Berg.

WINTER E. H., 2004, «The enemy within: Amba witchcraft and sociological theory», in John Middleton e E. H. Winter (eds.), Witchcraft and sorcery in East Africa, Londres, Routledge Library Editions, pp. 277-299. 


\section{NOTAS}

1. Por toda a África, diferentes trabalhos etnográficos têm registado a existência desse fenómeno que em Angola se designa mayombola e que recebe outras designações como mandandosha em Moçambique, nyongo (ekongo) nos Camarões, musukule na Tanzânia, econgo na Guiné Equatorial e sethotsela na África do Sul. Consultar para o efeito West (2009: 93), Geschiere (1997: 137-168), Sanders (2001: 170), Niehaus, Mohlala e Shokane (2001: 69-71), Beildelman (1963: 66), Martí (2011: 1-11), Lambek (1993: 249) e Rosny (1981: 112-126; 470-473).

2. As autoridades coloniais estabeleceram em 1933 a Reforma Administrativa Ultramarina (RAU), Decreto-lei 23:229, de 15 de Novembro, que institucionalizava a integração das autoridades tradicionais angolanas no aparelho administrativo colonial. A RAU, no capítulo dos deveres e das funções das autoridades tradicionais, no seu Artigo 99.․, § 9.‥ determinava que deviam estas impedir entre as populações nativas, as práticas de feitiçaria e adivinhações (FLORÊNCIO 2010: 10).

3. A informação usada para o estudo das actividades sobrenaturais discutidas neste texto, foram obtidas de material etnográfico recolhido e gravado em várias entrevistas orais feitas a diversos médicos tradicionais e a diferentes pessoas sobre o assunto em causa, nas províncias de Luanda, Kwandu-Kuvangu, Kwanza-Norte e Uíje, entre 2013 e 2015.

4. $O$ conceito de equilíbrio social envolve a visão de que um sistema social é feito de unidades interligadas de pessoas ou grupos cujos interesses são, por alguma razão, mantidos em balanço e quando ocorre um distúrbio, são feitos reajustamentos que têm o efeito de restaurar o balanço alterado (TURNER 1957: 161).

5. O uso do som produzido por caniços, utilizados como apitos, por feiticeiros, é relatado no Kwandu-Kuvangu, como uma forma de atrairem pessoas para serem aprisionadas e posteriormente transformadas em mão-de-obra escrava.

6. Martí (2011: 5), West (2009: 95) e Niehaus (2001: 26) observam que na Guiné Equatorial, Moçambique e África do Sul, respectivamente, a população relata que os feiticeiros enviam animais ferozes, como leões, leopardos e hienas para matar as suas vítimas, mas também se servem de cobras para o mesmo efeito. Segundo a população, os feiticeiros também disfarçam as suas acções transformando-se nesses animais ou fazendo-os cumprir as suas ordens.

7. Lambek (1993: 249-250) descreve pormenorizadamente essa dança sobre o sepulcro nas Ilhas Mayotte e Rosny (1981: 93) indica que o mesmo facto é também referenciado nos Camarões.

8. Jean e John Comaroff (1999a: 289) referem que na África do Sul, acredita-se que as almas capturadas são encarceradas em tambores de gasolina ou guardadas em barracões de ferramentas.

9. West (2009: 93), relata o uso de bananeiras pelos feiticeiros do planalto de Mueda em Moçambique, para substituir os cadáveres usados na mandandosha, isto é, o equivalente à mayombola. Chisanga, Sikazue, Kapembwa, Skazue e Nanyangwe (1999: 144-146) também relatam o uso de bananeiras pelos feiticeiros de Ulungu, na Zâmbia, para substituir os corpos das suas vítimas. Beidelman (2004: 66), relata igualmente que os feiticeiros de Kaguru, habitantes da parte central-este da Tanzânia, usam pessoas «mayomboladas» (musukule) para o trabalho escravo, retirando os seus corpos dos sepulcros e substituindo-os por troncos de bananeiras que faziam parecer-se com as vítimas, sem que os familiares destas se apercebam do sucedido. No KwanduKuvangu como a região não é favorável ao cultivo da banana, mas onde a presença de gado é maior, é relatado que os corpos são substituídos por caudas de animais.

10. Martí (2011: 5) relata que na Guiné Equatorial, um indivíduo cuja morte tinha sido atribuída a ekongo (mayombola) lançado por uma tia, irmã da sua mãe, que vivia em Espanha, quando esta enviou dinheiro à irmã para ajudá-la nas despesas do funeral do sobrinho que teve lugar na Guiné, a família não permitiu que ela tocasse no dinheiro recebido para que não fosse também contaminada pelo mesmo mal, pelo que, teve que ser o seu marido a recebê-lo. Rosny (1981: 
112-126) também relata a extraordinária luta que travam os médicos tradicionais nos Camarões para libertarem alguém dos efeitos do ekongo.

11. Na República do Congo, os seus habitantes falam da existência de uma aldeia de mortos (ibunga), composta por duplos (bakuya), mortos por um chefe através da feitiçaria (AUGÉ 1974: 87). Os Kaguru, habitantes da parte central-este da Tanzânia, dizem que nas montanhas há comunidades inteiras de mortos-vivos que dançam, casam e até fazem circuncisões, e que se ouvem choros durante a noite vindos dessas montanhas (BEIDELMAN 2004: 66).

12. Para a análise do caso de mayombola na província do Zaire, também se fez recurso à informação obtida de órgãos de comunicação social, como a Televisão Pública de Angola (TPA) e o Jornal de Angola. O programa TV Repórter da TPA, conduzido pela jornalista Joana Tomás, emitiu em dois programas consecutivos, nos dias 22 e 30 de Outubro de 2014, reportagens sobre o caso de mayombola verificado na aldeia Quimpemba, Comuna do Sumba, província do Zaire. O Jornal de Angola também publicou três reportagens sobre o assunto. A primeira, no dia 08 de Agosto de 2014, assinada pelos jornalistas Vanusa Cabimba e João Mavinga, com o título «Jovem regressa dois anos após "morrer": troca de cadáveres na morgue do hospital municipal pode estar na origem da insólita situação»; a segunda, no dia 04 de Outubro de 2014, assinada pelo jornalista Jaquelino Figueiredo, com o título «Morto ressuscitado: especialistas da DNIC investigam o caso» e a terceira no dia 18 de Outubro de 2014, também assinada pelo jornalista Jaquelino Figueiredo com o título «Caso polémico do Soyo: DNIC desmente história de suposta ressurreição - jovem implicado no crime é de nacionalidade congolesa e alega ter sido persuadido».

13. Geschiere (1997: 162-163) também analisa a ligação existente entre as estruturas de poder locais e os novos-ricos nos Camarões, observando que a legitimação da sua acumulação de riqueza por meios sobrenaturais é efectivada quando esses novos-ricos fazem doações aos responsáveis políticos comunitários, os fon.

14. No Kwandu-Kuvangu é relatado que as pessoas «kamutukulenizadas» são usadas como força de trabalho para espantar os pássaros que consomem as lavras de masambala, para a pesca, para a colheita de mel e também para a caça.

15. De acordo com muitas pessoas entrevistadas, hoje em dia «a mayombola até já se encontra na praça», isto é, no mercado.

\section{RESUMOS}

O mundo do oculto em Angola tem continuamente registado o uso de uma forma diferente de feitiçaria voltada para a obtenção de riqueza material, que se designa mayombola. De acordo com esta crença, o especialista em mayombola transforma as suas vítimas em mortos-vivos para os usar como trabalhadores escravos, para a acumulação de riqueza de quem dela se serve. Este texto analisa esta crença que se encontra disseminada por todo o país assim como pelo continente africano, fazendo recurso a material etnográfico recolhido e gravado em várias entrevistas orais feitas a diversos médicos tradicionais e a diferentes pessoas sobre o assunto em causa. Neste texto, a crença na mayombola é explicada com base nos conceitos de economia moral e economia de afeição, assim como são também feitas reflexões sobre a sua utilização como arte sobrenatural de enriquecimento, a sua ligação com o poder tradicional e a sua mercantilização.

The world of the occult in Angola has been continuously registering the use of a different type of witchcraft oriented towards the acquisition of material richness, which is called mayombola. 
According to this belief, the mayombola specialist transforms his victims in dead-alive to use them as slave workers, to accumulate wealth for the ones who use it. This text analyzes this belief which is disseminated all over the country as well as in the African continent, substantiated on ethnographic material collected and recorded from several oral interviews from traditional doctors and different respondents. In this text, the mayombola belief is explained based on the concepts of moral economy and moral affection, as well as are also made reflections about it utilization as supernatural art of enrichment and it connection to the traditional power and to it commodification.

\section{ÍNDICE}

Keywords: Mayombola, supernatural, belief, occult, moral economy, affection economy, accumulation, commodification

Palavras-chave: Mayombola, arte sobrenatural, crença, oculto, economia moral, economia de afeição, acumulação, mercantilização

\section{AUTOR}

\section{ODÍLIO FERNANDES}

odiliotfernandes@hotmail.com

Assistente de investigação do Centro de Investigação e Estudos de Sociologia (CIES) da Faculdade de Ciências Sociais (FCS) da Universidade Agostinho Neto (UAN).

Sociólogo, e possui o grau académico de Mestre em Sociologia Rural (Master of Science, MSc) obtido na Universidade de Missouri, Columbia, Estados Unidos da América (EUA). É actualmente Assistente de Investigação no Centro de Investigação e Estudos de Sociologia (CIES) da Faculdade de Ciências Sociais da Universidade Agostinho Neto, tendo como áreas de investigação de eleição a Sociologia Rural, a Sociologia da Religião, a Sociologia Histórica, a Sociologia dos Conflitos e a Sociologia do Quotidiano. É referee das edições da Revista Ciência e Tecnologia, do Ministério da Ciência e Tecnologia de Angola. Publicou As Rotas da incompreensão. Uma análise históricasociológica do mundo social Ndongo a partir de textos europeus dos séculos XVI e XVII (Luanda, Kilombelombe, 2014, 484 p. [«Ciências Humanas e Sociais - Série História de Angola»; 12]; «Sentido e poder em Georges Balandier: A antecipação de sentir o poder dos sistemas sociais», Mulemba-Revista Angola de Ciências Sociais (Luanda), Vol. IV, n.o 7, Maio de 2014, pp. 497-504. 